\title{
LECITINA, SILICONE E AMIDO NA ADUBAÇÃO FOLIAR DE COUVE (Brassica oleracea L.)
}

\author{
Lecithin, silicon and starch in the foliar feeding on collard green (Brassica oleracea L.)
}

\author{
Rosmany Aires Cunha Martins ${ }^{1}$, Hamilton Seron Pereira², Edésio Fialho Dos Reis ${ }^{2}$
}

\begin{abstract}
RESUMO
Objetivou-se, no presente trabalho, avaliar os efeitos que a lecitina, amido e silicone possam ter na eficiência da adubação foliar, utilizando-se sais e quelatos como fonte de micronutrientes. Para isso foi realizado um experimento em que avaliaram-se os efeitos da adição de diferentes adjuvantes em relação à absorção e translocação de zinco e manganês na forma de sais e quelatos. O delineamento utilizado foi o inteiramente casualizado, com seis repetições, com quatro fatores em estudo e dois níveis cada, perfazendo um fatorial $2 \times 2 \times 2 \times 2$, totalizando dezesseis tratamentos. Além dos tratamentos, foi adicionada testemunha como tratamento adicional, perfazendo, assim, um total de 102 parcelas. Cada parcela foi constituída por um vaso, contendo uma planta de couve-manteiga (Brassica oleracea L. var. acephala DC.). Os tratamentos constaram de combinações entre 2 fontes (sulfato e quelato) e de presença ou ausência de três substâncias na calda de pulverização: lecitina de soja desengordurada, um siliconado comercial e gel de amido de mandioca. A determinação dos efeitos constituiu-se na análise do teor de zinco e manganês nas folhas novas 30 dias após a pulverização. A adição de lecitina aumentou a absorção do sulfato de zinco ao passo que o produto siliconado aumentou a absorção do zinco quelatizado. Tanto a lecitina quanto o produto siliconado, quando adicionados à calda de pulverização, aumentaram o teor de manganês. O gel de amido não aumentou a absorção de nenhum micronutriente.
\end{abstract}

Termos para indexação: Adjuvantes, cutícula, manganês, quelatos, zinco.

\section{ABSTRACT}

The objective of the present work was to evaluate the effect of lecithin, starch and silicon may have in the efficiency of foliar feeding, using salts and chelates as source of nutrients. The experiment was carried out under greenhouse condition at Univerdidade Federal de Goiás (Jataí unit) - GO, set in a completely randomized design, with six replications, four factors in study and two levels each, making a $2 \times 2 \times 2 \times 2$ factorial arrangement, totalizing 16 treatments. Moreover, a control was added as an additional treatment, totalizing, 102 experimental units. Each experimental unit consisteed of by a vase of collard green plant (Brassica oleracea $\mathrm{L}$. var. acephala DC.). The treatments consisted of 2 minor nutrient sources (sulfate and chalate) and of absence and presence of three substance added to the spray solution: soydean lecithin de-waxed, a commercial silicon surfactant and starch. After analyses of the leaves, 30 days after the pulverization, it was clear that the amount of zinc and manganese was influenced by the adjutants and fertilizer. The use of lecithin increased the absorption of zinc sulfate whereas the use of silicon increased the absorption of zinc chelate. Both chelate and sulfate increased the absorption of manganese. Starch had no influence on micronutrient.

Index terms: Adjuvant, chelate, cuticle, manganese, zinc.

(Recebido em 2 de agosto de 2009 e aprovado em 6 de abril de 2010)

\section{INTRODUÇÃo}

O número crescente da população humana e a forte tendência à urbanização têm exigido um grande aumento na produção de alimentos, com o envolvimento de um menor número de pessoas na atividade agrícola. Assim, a agricultura tem que se tornar cada vez mais eficiente para aumentar a produtividade e a lucratividade, mantendo ou reduzindo a área plantada. Nesse desafio, a adubação é uma ferramenta imprescindível porque corrige as deficiências e/ou repõe nutrientes removidos pelas colheitas. Tradicionalmente, os macros e micronutrientes são aplicados no solo, mas há várias vantagens de se aplicar os micronutrientes via foliar (Bregonti et al., 2008). A aplicação de micronutrientes no solo está associada à dificuldade em distribuí-los uniformemente, já que a quantidade total por hectare é muito reduzida. A fertilização foliar permite uma distribuição uniforme desses nutrientes, o que reduz perdas e melhora o aproveitamento pelas plantas. Além disso, na adubação via solo, os nutrientes podem sofrer grandes perdas e/ou imobilização com os fenômenos de fixação (precipitação e adsorção) e lixiviação (Deuner et al., 2008). Tais perdas não ocorrem na fertilização via foliar, possibilitando a utilização de menores quantidades de adubos, tornando-os, consequentemente, mais eficientes. Possibilitar a utilização de uma menor

\footnotetext{
1Universidade Estadual de Goiás/UEG - Unu Jataí - Leo Lince - 610 - Setor Aeroporto - 75800-064 - rosmany14@hotmail.com 2Universidade Federal de Goiás/UFG - Jataí - GO
} 
quantidade de micronutrientes é de grande importância para a agricultura porque fontes solúveis de micronutrientes apresentam custo elevado. Entretanto, sabe-se que as folhas são hidrorrepelentes e que, devido à tensão superficial da água, as gotas da calda de pulverização podem ter apenas uma pequena área de contato com as folhas, o que diminui a capacidade de absorção dos nutrientes. Um surfactante, como os adjuvantes siliconados, é capaz de diminuir a energia das ligações entre as moléculas de água, diminuindo a tensão superficial da gota de pulverização. Os siliconados podem reduzir o ângulo de contato das gotas sobre a superfície foliar e permitir um maior cobrimento da folha pela calda (Camargo $\&$ Silva, 1990; Prado et al., 2008). A lecitina, outro adjuvante em potencial tem a capacidade de formar micelas. Essa propriedade ocorre devido às cadeias apolares e cabeça polar dos fosfolipídios. Para analisar os efeitos dos adjuvantes penetrantes como a lecitina, Prado et al. (2008) realizaram estudos para avaliar sua eficiência em aplicações de fitorreguladores e concluíram que a lecitina potencializa os efeitos dos hormônios empregados. Por último, o amido gelatinizado apresenta comportamento aderente e por isso é muito usado na indústria de adesivos (Teixeira et al., 2005). Um adjuvante aderente pode trazer benefícios para a adubação foliar por aumentar a viscosidade, mantendo a gota em estado líquido por mais tempo. Isso é vantajoso, pois os micronutrientes só podem ser absolvidos enquanto em solução (Prado et al., 2008). Alem disso, por ser aderente, o amido pode evitar que a gota escorra por ação da gravidade. Devido a uma preocupação ambiental, a EMATER/RS iniciou pesquisas em 1997 para desenvolver um adesivo que fosse ecológico, sustentável e que fosse produzido pelo próprio produtor. A partir de testes, constataram que o amido de trigo apresentava boa atuação como espalhante adesivo (Emater/RS, 2009).

\section{MATERIAL E MÉTODOS}

O experimento foi conduzido entre março e agosto de 2008. Foram utilizadas sementes de couve-manteiga híbrida HI-Crop (Brassica oleracea L. var. acephala DC.). O solo utilizado foi coletado no município de Jataí a uma profundidade entre 20 a $40 \mathrm{~cm}$, o qual foi classificado como Neossolo Quartzrenico Ortico. A caracterização química e física do solo foi a seguinte: argila 94,5 $\mathrm{g} \mathrm{kg}^{-1}$, silte $22,6 \mathrm{~g} \mathrm{~kg}^{-1}$, areia fina 534,9 $\mathrm{g} \mathrm{kg}^{-1}$, areia grossa $348,0 \mathrm{~g} \mathrm{~kg}^{-1}$, matéria orgânica 7,0 $\mathrm{g} \mathrm{kg}^{-1}, \mathrm{pH}\left(\mathrm{CaCl}_{2}\right)=4, \mathrm{Ca} 0,1 \mathrm{cmol}_{\mathrm{c}} \mathrm{dm}^{-3}$,

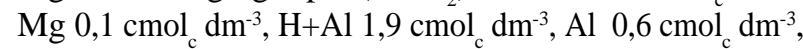
$\mathrm{K} 24 \mathrm{mg} \mathrm{dm}^{-3}$, P (mehlich) $1,0 \mathrm{mg} \mathrm{dm}^{-3}$, Saturação por Bases

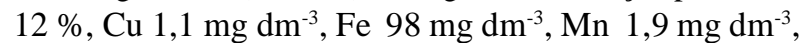
$\mathrm{Zn} 0,6 \mathrm{mg} \mathrm{dm}^{-3}$. A quantidade de $\mathrm{CaCO}_{3}$ e $\mathrm{MgCO}_{3}$ aplicada ao solo foi calculada tomando-se os valores da capacidade de troca catiônica (CTC) e saturação por bases (SB) do solo e ainda o valor desejado para atingir a saturação por bases de $70 \%$, que é a recomendável para a cultura de hortaliças (Filgueira, 2003). Após os cálculos, foram incorporados 2,59 $\mathrm{g}$ de $\mathrm{CaCO}_{3}$ PAe $0,58 \mathrm{~g}$ de $\mathrm{MgCO}_{3} \mathrm{PA}$ em cada vaso, 30 dias antes do transplante das mudas. Durante esse período, os vasos foram irrigados para favorecer a neutralização da acidez. $\mathrm{O}$ delineamento utilizado foi o inteiramente casualizado, com seis repetições, com quatro fatores em estudo e dois níveis cada, perfazendo um fatorial $2 \times 2 \times 2 \times 2$, totalizando dezesseis tratamentos. Além dos tratamentos, foi adicionada testemunha como tratamento adicional, perfazendo, assim, um total de 102 parcelas. Cada parcela foi constituída por um vaso contendo uma planta de couve-manteiga. Os tratamentos constaram de combinações entre 2 fontes (sulfato e quelato) e de presença ou ausência de três substâncias na calda de pulverização: lecitina de soja desengordurada (L), um siliconado comercial (S) e gel de amido (A). As combinações foram: (QUELATO - $\mathrm{L}_{0} \mathrm{~S}_{0} \mathrm{~A}_{0}, \mathrm{~L}_{\mathrm{o}} \mathrm{S}_{0} \mathrm{~A}_{1}, \mathrm{~L}_{\mathrm{o}} \mathrm{S}_{1} \mathrm{~A}_{0}, \mathrm{~L}_{0} \mathrm{~S}_{1} \mathrm{~A}_{1}$, $\mathrm{L}_{1} \mathrm{~S}_{0} \mathrm{~A}_{0}, \mathrm{~L}_{1} \mathrm{~S}_{0} \mathrm{~A}_{1}, \mathrm{~L}_{1} \mathrm{~S}_{1} \mathrm{~A}_{\mathrm{o}}, \mathrm{L}_{1} \mathrm{~S}_{1} \mathrm{~A}_{1}$ e SULFATO - L $\mathrm{S}_{0} \mathrm{~A}_{\mathrm{o}}$, $\mathrm{L}_{0} \mathrm{~S}_{0} \mathrm{~A}_{1}, \mathrm{~L}_{0} \mathrm{~S}_{1} \mathrm{~A}_{0}, \mathrm{~L}_{0} \mathrm{~S}_{1} \mathrm{~A}_{1}, \mathrm{~L}_{1} \mathrm{~S}_{0} \mathrm{~A}_{0}, \mathrm{~L}_{1} \mathrm{~S}_{0} \mathrm{~A}_{1}, \mathrm{~L}_{1} \mathrm{~S}_{1} \mathrm{~A}_{0}, \mathrm{~L}_{1} \mathrm{~S}_{1} \mathrm{~A}_{1}$, ) sendo zero para ausência e 1 para presença. O plantio de couve-manteiga híbrida foi realizado em bandejas de poliestireno (isopor) com 128 células piramidais cada, no dia 26 de março e a emergência ocorreu no dia 31 de março. As mudas foram cultivadas em sementeira até atingirem 6 $\mathrm{cm}$. O transplante de mudas ocorreu 28 dias após a emergência (DAE). Para nutrição com macronutrientes, levaram-se em consideração os resultados das análises do solo e obedeceram-se os tratos culturais sugeridos por Malavolta (2006). Para fazer a solução com micronutrientes a ser aplicada nas folhas, utilizou-se como fonte sulfatos e quelatos em quantidades recomendadas no manual do Malavolta (1981) sobre adubação foliar. Para preparar a fonte de sulfato, colocou-se $1,2 \mathrm{~g}$ de $\mathrm{ZnSO}_{4}$ e $0,81 \mathrm{~g}$ de $\mathrm{MnSO}_{4}$ por litro de água destilada. A calda foi preparada imediatamente antes da aplicação. Para preparar a fonte de quelato, foram misturados: $\mathrm{ZnSO}_{4}$ com EDTA, em quantidades estequiométricas; e $\mathrm{MnSO}_{4}$ com EDTA também em quantias estequiométricas (Fernandez et al., 2006). As misturas Zn/ EDTA e Mn/ EDTA foram colocadas em recipientes separados e levados para arejar por 24 horas. Para preparar o gel de amido, aqueceu-se $40 \mathrm{~g}$ de fécula de mandioca em $800 \mathrm{~mL}$ de água destilada. A temperatura foi elevada até $60^{\circ} \mathrm{C}$ para induzir a gelificação dos cristais de amido e formar um gel transparente e aderente (Ribeiro \& Sevavalli, 2004). Antes da pulverização, o amido foi levado ao laboratório para análise em micronutrietntes, sendo 
encontrados: $\mathrm{Cu}\left(5 \mathrm{mg} \mathrm{kg}^{-1}\right) ; \mathrm{Fe}$ (253 $\left.\mathrm{mg} \mathrm{kg}^{-1}\right) ; \mathrm{Mn}\left(10 \mathrm{mg} \mathrm{kg}^{-1}\right)$ $\mathrm{Zn}\left(10 \mathrm{mg} \mathrm{kg}^{-1}\right)$. Para preparar a lecitina desengordurada, utilizamos a metodologia descrita por Teberikler et al. (2001). A lecitina bruta foi, inicialmente, solubilizada com éter etílico. Em seguida, acrescentou-se acetona PA. Os fosfolipídios polares precipitaram e o óleo (lipídeo apolar) ficou solúvel, juntamente com o éter e acetona. Essa mistura foi levada para centrifuga a $3000 \mathrm{rpm}$. Decantouse, então, a parte líquida. Em seguida, lavou-se o precipitado 4 vezes com acetona PA para retirar todo o lipídeo apolar. Restou uma pasta amarela-clara no tubo de ensaio. Essa pasta, denominada lecitina desengordurada, foi levada à estufa para secar. O surfactante siliconado é um produto comercial e seu preparo seguiu orientações do fabricante. Sessenta e cinco DAE, todas as plantas, com exceção das testemunhas, receberam pulverização foliar contendo $1,2 \mathrm{~g} \mathrm{~L}^{-1}$ de $\mathrm{ZnSO}_{4}+0,81 \mathrm{~g} \mathrm{~L}^{-1}$ de $\mathrm{MnSO}_{4}$ ou equivalente, em gramas, de $\mathrm{Zn} / \mathrm{Mn}$ na forma de quelato de zinco + quelato de manganês. Nos tratamentos que receberam lecitina, foram colocados $1,7 \mathrm{~g} \mathrm{~L}^{-1}$ de lecitina para cada litro da calda. Essa é solúvel e foi rapidamente homogeneizada na solução. Nos tratamentos que receberam o silicone, utilizaram $3 \mathrm{~mL}$ do produto, para cada litro da calda. Para cada tratamento que recebeu amido, foi colocado o gel na calda, na proporção de $20 \%$ (v/v). O volume da calda utilizada foi aproximadamente $50 \mathrm{~mL}$ de calda nutritiva por vaso. Durante a pulverização, o solo dos vasos foi protegido com plásticos e tecidos absorventes para impedir que a calda de pulverização escorresse para dentro dos mesmos. Com esse controle, evita-se a contaminação do solo com os nutrientes da pulverização e a interferência nos resultados. $\mathrm{O}$ fertilizante foliar foi pulverizado, com aplicador manual, na planta inteira (Fernandez et al., 2006). Aos noventa e cinco DAE foram coletadas 3 folhas verdadeiras a partir do ápice. Depois de lavadas, as folhas secaram ao ar livre e, em seguida, foram levadas para a estufa a $60^{\circ} \mathrm{C}$ até atingirem peso constante. As folhas secas foram moídas e a extração do manganês e zinco ocorreu segundo metodologia descrita por Silva (1999). Pesou-se 0,5 g do material vegetal que foram transferidos para o tubos de digestão, adicionando $6 \mathrm{~mL}$ da mistura de ácido nítrico e $2 \mathrm{~mL}$ de ácido perclórico (proporção de 3:1). As amostras foram levadas para o bloco digestor e aquecias. Após frio, transferiram-se as amostras para um balão volumétrico e completou-se o volume para $50 \mathrm{~mL}$ com água deionizada. As amostras foram levadas, no mesmo dia, para o laboratório para quantificação total de $\mathrm{Zn}$ e Mn. Os micronutrientes Mn Zn foram determinados através da técnica de Espectrometria de Absorção Atômica (AAS). Os dados experimentais foram submetidos à análise de variância e testes de médias com auxílio do aplicativo computacional Sistema para Análise Estatística (SAEG). Quando ocorreu significância das interações entre os fatores em estudo, as mesmas foram decompostas e as médias comparadas pelo teste de Tukey, ao nível de $1 \%$ e $5 \%$ de significância.

\section{RESULTADOS E DISCUSSÃO}

A análise de variância dos teores de $\mathrm{Zn}$ indica que, na absorção, existe interação entre fonte e amido e entre fonte, lecitina e silicone indicando que, alterando a fonte ou a presença ou ausência do coadjuvante, a resposta em termos de absorção é influenciada. $\mathrm{O}$ amido não influencia na absorção do metal $\mathrm{Zn}$ quando sulfato é utilizado como fonte de zinco (Tabela 1). Apesar de ser um adesivo, essa substância não contribui para a absorção do micronutriente. Existem relatos sobre os efeitos positivos do amido de trigo como adjuvante na adubação foliar (Emater/RS, 2009), mas esse benefício não é observado com o uso do amido de mandioca. Isso pode ocorrer porque, apesar de facilitar a aderência da calda na folha, o amido pode não ter facilitado a entrada dos nutrientes no simplasto. Para ser eficiente, o fertilizante foliar tem que penetrar na cutícula e ser transportado para toda a planta, inclusive para as partes novas (Camargo \& Silva, 1990; Sartori et al., 2008). Utilizando-se fonte de nutrientes quelatizadas, observase que o gel de amido leva a uma redução da absorção de zinco. Por ser um poderoso adesivo, esse gel permanece na superfície da planta após a pulverização, mesmo após a secagem. A molécula de amido é um polímero orgânico que certamente interage com a molécula do EDTA através de ligações intermoleculares fortes, ficando ambas as moléculas retidas na superfície da folha que recebeu a pulverização. Se o quelato não atravessar a cutícula, o zinco não será aproveitado pela planta em seu metabolismo, ficando também impossível o transporte do metal para as partes novas da planta. As ligações intermoleculares entre o EDTA e o amido são do tipo pontes de hidrogênio as quais são interações químicas em que o átomo de hidrogênio é atraído simultaneamente por átomos muito eletronegativos, atuando como ponte entre eles (Kotz \& Treichel Júnior, 2002a,b). Cada molécula de EDTA possui 6 regiões disponíveis para ligações de hidrogênio enquanto o polímero de glicose possui várias hidroxilas para esse mesmo tipo de ligação. Também foi constatado que a fonte quelato foi superior à fonte sulfato na absorção de zinco, na ausência do adesivo amido (Tabela 1). 
Tabela 1 - Valores médios do teor de zinco $\left(\mathrm{mg} \mathrm{kg}^{-1}\right)$, em folhas de couve 30 dias após pulverização de $\mathrm{Zn}$, em função da presença/ ausência do amido e em função das fontes sulfato e quelato.

\begin{tabular}{lll}
\hline \multirow{2}{*}{ Fonte } & \multicolumn{2}{c}{ Amido } \\
\cline { 2 - 3 } & Presença & Ausência \\
\hline Sulfato & $21,21 \mathrm{Aa}$ & $19,46 \mathrm{Ab}$ \\
Quelato (EDTA) & $20,04 \mathrm{Ba}$ & $24,12 \mathrm{Aa}$ \\
\hline * na mesma linha, médias seguidas de mesma letra maiúsculas e na \\
mesma coluna, médias seguidas de mesma letra minúscula não \\
diferem estatisticamente pelo teste de Tukey, ao nível de 1\%.
\end{tabular}

Canesin \& Buzetti (2007), em uma pesquisa sobre produção de pera, encontrou que aplicando-se $\mathrm{Zn}$ foliar quelatizado obtém-se resultados positivos muito superiores aos da testemunha, o que não ocorre com o uso de $\mathrm{Zn}$ como sulfato. O (EDTA- Zn) refere-se a uma molécula orgânica com a configuração em anel que se origina quando o metal (cátion) $\mathrm{Zn}^{+2}$ combina com dois ou mais grupos doadores de elétrons existentes numa única molécula. A molécula orgânica funciona como duas pinças numa reação que é reversível (Malavolta, 2006). Isso impede a fixação do zinco na cutícula além de evitar a sua precipitação na calda. O EDTA-Zn protege os nutrientes contra as reações químicas que ocorrem na água de pulverização e na cutícula das folhas. Na forma quelatizada, os nutrientes permanecem em forma solúvel por longo tempo, sendo mais bem absorvido pelas folhas (Serviço Brasileiro de Respostas Técnicas-SBRT, 2009). Isso explica a superioridade da fonte quelato sobre a fonte sulfato. A superioridade da fonte quelatizada sobre o sulfato não foi observada no grupo que utilizou o adesivo amido. Isso provavelmente ocorreu devido a interações intermoleculares entre o gel de amido com o EDTA. O gel de amido, provavelmente por ser um adesivo, interage também com outros adjuvantes, como será discutido mais adiante. As tabelas 2, 3 e 4 apresentaram os testes de médias para os teores de zinco após desmembramento da interação entre fonte, lecitina e silicone. O uso de lecitina acarreta um aumento significativo do teor de zinco nas folhas de couve como indica o teste de média (Tabela 2). Esse resultado demonstra a importância da adição de um adjuvante penetrante na calda de pulverização. Butler Ellis (1997) verificou que a lecitina (Agrydine - LI-700, 2008) aumentou o tamanho da gota quando adicionada ao pesticida glifosato, reduzindo substancialmente a deriva, além de aumentar a deposição do herbicida na plantação. No presente ensaio, a absorção e transporte de zinco é aumentado pela lecitina, provavelmente devido à sua propriedade tensoativa. Com uma menor tensão superficial, a gota da solução tem maior área de contato com a folha, aumentando a absorção dos nutrientes (Camargo \& Silva, 1990). Há pouca pesquisa publicada sobre a eficiência de surfactantes anfóteros. Outro fator que pode ter contribuído para um aumento do teor de zinco é que a lecitina promove uma mudança temporária da cutícula da folha, facilitando a penetração do $\mathrm{Zn}^{+2}$. Esse micronutriente, devido a sua carga positiva, tem dificuldade em atravessar a cutícula, a qual é formada por ceras apolares, que impedem a passagem do $\mathrm{Zn}^{+2}$, e cutina de carga negativa, que retém o $\mathrm{Zn}^{+2}$ (Camargo \& Silva, 1990).

Tabela 2 - Valores médios do teor de zinco $\left(\mathrm{mg} \mathrm{kg}^{-1}\right)$, obtidos das folhas de couve, 30 dias após pulverização de $\mathrm{Zn}$, em função da presença ou ausência de lecitina dentro dos níveis de fonte e silicone.

\begin{tabular}{llcl}
\hline \multirow{2}{*}{ Fonte } & \multirow{2}{*}{ Silicone } & \multicolumn{2}{c}{ Lecitina } \\
\cline { 3 - 4 } & & Presença & Ausência \\
\hline Sulfato & Presença & $24,33 \mathrm{a}$ & $19,00 \mathrm{~b}$ \\
Sulfato & Ausência & $21,25 \mathrm{a}$ & $16,75 \mathrm{~b}$ \\
Quelato & Presença & $22,92 \mathrm{a}$ & $24,42 \mathrm{a}$ \\
Quelato & Ausência & $23,08 \mathrm{a}$ & $17,92 \mathrm{~b}$ \\
\hline
\end{tabular}

* na mesma linha, médias seguidas de mesma letra não diferem estatisticamente pelo teste de Tukey, ao nível de 5\%.

Não apresentou diferença significativa a utilização de dois adjuvantes, silicone e lecitina, juntamente com a fonte EDTA-Zn. Os adjuvantes e o tipo de adubo podem interagir uns com os outros e inibir os possíveis efeitos da mistura fertilizantes/ adjuvante. Interações entre os adjuvantes e o EDTA provavelmente ocorrem devido às fortes ligações intermoleculares, levando a um complexo que não atravessa a cutícula. O quelato aumentou a absorção de zinco em mais de $28 \%$, em relação à fonte sulfato (Tabela 3), na ausência de lecitina e presença de silicone. Nas demais comparações, dentro dessa interação a fonte não influencia no teor de zinco na folha. Em um experimento com tangerina, Brennan (1991) observaram que fontes quelatizadas possuem maior eficiência que sais de sulfato, pois obtêm bons resultados mesmo utilizando menores doses de adubo. Na forma quelatizada, os nutrientes permanecem em forma solúvel por longo tempo, sendo mais bem absorvidos pelas folhas (SBRT, 2009). Isso explica a superioridade da fonte quelato sobre a fonte sulfato. A Tabela 3 evidenciou que o quelato é superior como fonte de zinco e que o silicone tem um papel 
fundamental para que o quelato tenha um melhor desempenho. Os organossiliconados diminuem o ângulo de contato entre a gota e a folha, permitindo um maior contato da calda de pulverização com a superfície da folha. Isso caracteriza a diminuição da tensão superficial da água (Montório, 2004). Esse contato mais íntimo entre a calda de pulverização e a folha favorece a absorção do quelato.

Tabela 3 - Valores médios do teor de zinco $\left(\mathrm{mg} \mathrm{kg}^{-1}\right)$, obtidos das folhas de couve, 30 dias após pulverização de $\mathrm{Zn}$, em função da fonte quelato e sulfato, dentro dos níveis de lecitina e silicone.

\begin{tabular}{llll}
\hline \multirow{2}{*}{ Lecitina } & \multirow{2}{*}{ Silicone } & \multicolumn{2}{c}{ Fonte } \\
\cline { 3 - 4 } & & Sulfato & Quelato \\
\hline Presença & Presença & $24,33 \mathrm{a}$ & $22,92 \mathrm{~b}$ \\
Presença & Ausência & $21,25 \mathrm{a}$ & $23,08 \mathrm{~b}$ \\
Ausência & Presença & $19,00 \mathrm{a}$ & $24,42 \mathrm{a}$ \\
Ausência & Ausência & $16,75 \mathrm{a}$ & $17,92 \mathrm{~b}$ \\
\hline
\end{tabular}

* na mesma linha, médias seguidas de mesma letra não diferem estatisticamente pelo teste de Tukey, ao nível de 5\%.

Entretanto, novamente ficou evidente que a presença da lecitina junto com os fatores quelato/silicone impede resultados satisfatórios. Pode ser constatado que os resultados positivos, seja do quelato ou do silicone, não devem conter um terceiro adjuvante. Provavelmente, haveria formação de complexos, os quais impedem a passagem do nutriente na cutícula. $\mathrm{O}$ produto comercial constituído de silicone e glicol melhorou a absorção do quelato de zinco, na ausência de lecitina (Tabela 4). Nas demais comparações, dentro dessa interação, o silicone não influencia no teor de zinco na folha. Fernández et al. (2006) observaram que os valores da tensão superficial de compostos de ferro eram menores quando se usa surfactante organossiliconado Silwet L-7607. Gent et al. (2003) comcluiram que os organosiliconados são os surfactantes que mais completamente cobriram as folhas de batatas, feijões e cebolas, em um experimento com fungicidas. Os organossiliconados possuem uma cadeia lipofílica e uma hidrofílica (Green et al., 2000; Montório, 2004). Compostos anfifílicos diminuem o ângulo de contato entre a gota e a folha, permitindo um maior contato da calda de pulverização com a superfície da folha (Camargo \& Silva, 1990).

Este bom desempenho do silicone ocorre quando é utilizado o EDTA-Zn, provavelmente por que essa fonte envolve a carga do $\mathrm{Zn}^{+2}$, permitindo que o micronutriente se beneficie da maior área de contato que o silicone proporciona. Mais uma vez, ficou evidenciado que os resultados positivos, seja do quelato ou do silicone, não devem conter um terceiro adjuvante. Quanto ao manganês, a análise de variância indica que não houve interações entre os diferentes fatores. Os testes de médias para lecitina, fonte, silicone e amido estão apresentados na Tabela 5. A lecitina aumenta a absorção de manganês em $7,2 \%$. Esse fosfolipídio cria uma passagem que permite a entrada dos micronutrientes presentes no adubo foliar.

Tabela 4 - Valores médios do teor de zinco $\left(\mathrm{mg} \mathrm{kg}^{-1}\right)$, obtidos das folhas de couve, 30 dias após pulverização de $\mathrm{Zn}$, em função da presença ou ausência de silicone dentro dos níveis de fonte e lecitina.

\begin{tabular}{llcl}
\hline \multirow{2}{*}{ Fonte } & \multirow{2}{*}{ Lecitina } & \multicolumn{2}{c}{ Silicone } \\
\cline { 3 - 4 } & & Presença & Ausência \\
\hline Sulfato & Presença & $24,33 \mathrm{a}$ & $21,25 \mathrm{a}$ \\
Sulfato & Ausência & $19,00 \mathrm{a}$ & $16,75 \mathrm{a}$ \\
Quelato & Presença & $22,91 \mathrm{a}$ & $23,08 \mathrm{a}$ \\
Quelato & Ausência & $24,42 \mathrm{a}$ & $17,91 \mathrm{~b}$ \\
\hline
\end{tabular}

* na mesma linha, médias seguidas de mesma letra não diferem estatisticamente pelo teste de Tukey, ao nível de 5\%.

Tabela 5 - Valores médios do manganês $\left(\mathrm{mg} \mathrm{Kg}^{-1}\right)$, obtidos das folhas de couve, 30 dias após pulverização de $\mathrm{Mn}$, em função da fonte do micronutriente e adjuvantes.

\begin{tabular}{llc}
\hline \multicolumn{2}{c}{ TRATAMENTO } & Mn \\
\hline Fonte & & \\
& Quelato & $98,52 \mathrm{a}$ \\
& Sulfato & $97,95 \mathrm{a}$ \\
\hline Lecitina & & \\
& Presença & $101,83 \mathrm{a}$ \\
& Ausência & $94,64 \mathrm{~b}$ \\
\hline Amido & & \\
& Presença & $98,93 \mathrm{a}$ \\
& Ausência & $97,54 \mathrm{a}$ \\
\hline Silicone & & \\
& Presença & $101,45 \mathrm{a}$ \\
& Ausência & $95,02 \mathrm{~b}$ \\
\hline
\end{tabular}

Em cada coluna, dentro de cada fator, médias seguidas por letras diferentes diferem pelo teste Tukey, a 5\% de probabilidade.

$\mathrm{O}$ adjuvante amido não afetou significativamente a absorção de manganês adicionado na calda de pulverização. A fonte sulfato e quelato não apresentaram diferença significativa na absorção do Mn. O silicone 
intensifica a absorção de manganês pelas folhas como pode ser visto na Tabela 5. Ao aumentar o tamanho da gota, o silicone aumenta também a área de contato da calda de pulverização com a folha, proporcionando uma melhor absorção do Mn. Os valores de F para interação de quarta ordem do zinco e manganês foram não significativos.

\section{CONCLUSÕES}

A fonte de zinco quelatizada (Zn-EDTA), quando preparada com aditivo à base de silicone, proporciona uma maior absorção e translocação de $\mathrm{Zn}^{+2}$ para partes novas, quando comparada com a fonte sulfato de zinco $\left(\mathrm{ZnSO}_{4}\right)$. Essa superioridade não é notada quando, juntamente com o aditivo à base de silicone, coloca-se amido ou lecitina na calda de pulverização. Quando lecitina desidratada é adicionada à calda, aumenta-se a absorção do $\mathrm{Zn}$ na forma de $\mathrm{ZnSO}_{4}$. A lecitina também aumenta a absorção do ZnEDTA, desde que não se utilize silicone conjuntamente. $\mathrm{O}$ uso da lecitina também aumentou a absorção do manganês. Utilizando-se adjuvante siliconado, aumenta-se a absorção do $\mathrm{Zn}$ na forma de $\mathrm{Zn}$-EDTA, desde que não se utilize lecitina conjuntamente. $\mathrm{O}$ adjuvante siliconado também aumentou a absorção do $\mathrm{Mn}$. O amido não aumentou a absorção de Zn e nem do Mn. Foi observado que a utilização de mais de um adjuvante na calda de pulverização inibe a absorção dos micronutrientes.

\section{REFERÊNCIAS BIBLIOGRÁFICAS}

BUTLER ELLIS, M.C.;TUCK, C.R.,MILLER, P. C. H. The effect of some adijuntants on sprays produced by agricultural flast fan nozzles. Crop Protectionv. 16, n. 1, p. 40-50, 1997

BRENNAN, R. F. Effectiveness of zinc sulfate and zinc chelate as foliar sprays in alleviating zinc deficiency of wheat grown on zinc-deficient soils in Western Australia. Australian Journal of Experimental Agriculture, v. 3, n. 6, p. 831-834, 1991.

CAMARGO, P.N. de; SILVA, O. Manual de nutrição foliar. São Paulo: Instituto Campineiro de Ensino Agrícola, 1990. 251p.

CANESIN, R.C.F.; BUZETTI, S. Efeitos da aplicação foliar de boro e zinco sobre a produção e os teores da SST e AAT dos frutos da pereira japonesa e da pinheira. Revista Brasileira da Fruticultura, Jaboticabal, v.29, n.2, ago. 2007.

DEUNER, S.; NASCIMENTO, R. do; FERREIRA, L.S.; BADINELLI, P.G.; KERBER, R.S. Adubação foliar e via solo de nitrogênio em plantas de milho em fase inicial de desenvolvimento. Ciência e Agrotecnologia, Lavras, v.32, p.1359-1365, 2008.

EMATER/RS. Alternativa tecnológica: farinha de trigo: espalhante adesivo ecológico. Disponível em: <http:// 'www.pronaf.gov.br/dater/arquivos/2014419906.pdf $>$. Acesso em: 13 fev. 2009.

\section{EMPRESA BRASILEIRA DE PESQUISA \\ AGROPECUÁRIA. Novos rumos na produção de hortaliças. Disponível em: <http:// ,www.cnph.embrapabr/public/textos/texto1.htmì Acesso em: 26 out. 2008.}

FERNANDEZ, V.; RIO, V.D.; ABADIA, J.; ABADIA, A Foliar iron fertilization of peach. Plant Soil, Zaragoza, p.239-252, Oct. 2006.

FILGUEIRA, F.A.R. Novo manual de olericultura: agrotecnologia moderna na produção e comercialização de hortaliças. 2.ed. Viçosa, MG: UFV, 2003. 412p.

GENT, D.H.; SCHWARTZ, H.F.; NISSEN, S.J. Effect of commercial adjuvants on vegetable crop fungicide coverage, absorpition, and efficacy. Plant Disease, Quebec, v.87, n.5, p.591-597, May 2003.

KOTZ, J.C.; TREICHEL JÚNIOR, P. Química e reações químicas. 4.ed. Rio de Janeiro: LTC, 2002a. v.1, 345p.

KOTZ, J.C.; TREICHEL JÚNIOR, P. Química e reações químicas. 4.ed. Rio de Janeiro: LTC, 2002b. v.2, 345p.

MALAVOLTA, E. Elementos de nutrição mineral de plantas. São Paulo: Ceres, 1981. 251p.

MALAVOLTA, E. Manual de nutrição mineral de plantas: adubos e adubação. São Paulo: Agronômica Ceres, 2006. 638p.

MONTÓRIO, G.A. Definição de um coeficiente de eficácia para estudo para estudo de tensão superficial com surfactantes siliconados e não siliconados. Scientia Agrária Paranaensis, Belém, v.3, n.1, p.26-34, 2004.

MONTÓRIO, G.A.; VELINI, E.V.; MACIEL, C.D.G.; MONTORIO, T. Eficiência dos surfactantes de uso agrícola na redução da tensão superficial. Disponível em: 〈http://www.upf.br/rbherbicidas/download RBH228.pdf $>$. Acesso em: 10 nov. 2008. 
PRADO, A.M.; KAUER, C.; SOTO, P.; SOLAR, C.E.D.; SOZA, J.A.; DEPALLENS, D. Adyuvantes, sus propiedades e efectos en las aplicaciones de fitorreguladores. Disponível em: <http://Www.uvademesa.cl/ARCHIVOS\%20PDF/ iAdyuvantes\%20aconex\%20 parte $\% 202 . \mathrm{df} y$. Acesso em 4 nov. 2008 .

RIBEIRO, E.P.; SERAVALLI, E.A.G. Química de alimentos. São Paulo: E.Blûcher, 2004. 184p.

SARTORI, R.H.; BOARETTO, A.E.; MURAOKA, T.; VILLANUEVA, F.C.A.; FERNANDEZ, H.M.G.

Redistribuição do zinco em laranjeiras. Revista Laranja, Cordeirópolis, v.29, p.87-97, 2008.

SERVIÇO BRASILEIRO DE RESPOSTAS TÉCNICAS. Lecitina de soja. Disponível em: <http://sbrtv1.ibict.bri upload/

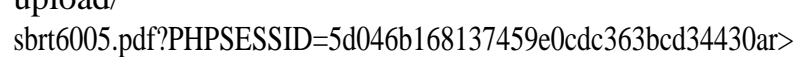
Acesso em: 10 nov. 2008.

SERVIÇO BRASILEIRO DE RESPOSTAS TÉCNICAS. Quelato de micronutrientes para a agricultura.
Disponível em: 〈htttp://Www.sbrtibict.br . Acesso em: 10 jan. 2009.

SERVIÇO BRASILEIRO DE RESPOSTAS TÉCNICAS. Utilização de lecitinas de soja e girassol na panificação. Disponível em: 〈http://Www.sbrt.ibict.br . Acesso em: 10 nov. 2008.

SILVA, F.C. da. Manual de análises químicas de solos, plantas e fertilizantes. Brasília: Embrapa, 1999. 370p.

TEBERIKLER, L.; KOSEOGLU, S.; AKGERMAN, A. Deoling of crude lecithin using supercritical carbon dioxide in the presence of co-solvents. Journal of Food Science, Chicago, v.66, n.6, p.850-853, 2001.

TEIXEIRA, E.M.; ROZ, A.L.; CARVALHO, A.J.F.; CURVELO, A.A.S. Preparation and characterisation of thermoplastic starches from cassava starch, cassava root and cassava bagasse. Macromolecular Symposia, v.229, p.266-275, 2005. 